\title{
What is Deep Disagreement?
}

\author{
Chris Ranalli ${ }^{1} \mathbb{C}$
}

Published online: 29 October 2018

(c) The Author(s) 2018

\begin{abstract}
What is the nature of deep disagreement? In this paper, I consider two similar albeit seemingly rival answers to this question: the Wittgensteinian theory, according to which deep disagreements are disagreements over hinge propositions, and the fundamental epistemic principle theory, according to which deep disagreements are disagreements over fundamental epistemic principles. I assess these theories against a set of desiderata for a satisfactory theory of deep disagreement, and argue that while the fundamental epistemic principle theory does better than the Wittgensteinian theory on this score, the fundamental epistemic principle theory nevertheless struggles to explain the variety of deep disagreement.
\end{abstract}

Keywords Deep Disagreement $\cdot$ Hinge propositions $\cdot$ Fundamental epistemic principles $\cdot$ Wittgenstein $\cdot$ Normative disagreement $\cdot$ Metaphysical disagreement

\section{Introduction}

Recent work on deep disagreement has tended to focus on various epistemic issues, such as whether deep disagreements are rationally resolvable (and if so, how), or whether deep disagreement supports epistemic relativism. ${ }^{1}$ However, this work has tended to jettison the important metaphysical question of what deep disagreement consists in. And while views about the nature or metaphysics of deep disagreement have been proposed in the literature, they tend to be cursory or are otherwise tied too closely to the epistemic question of whether they are rationally resolvable. ${ }^{2}$ However, we might think that we should step back and ask about the nature of deep disagreement directly, for example, by asking what such disagreements consist in and what kinds of attitudes are at stake in such cases. As it stands, we lack any clear criteria for what deep disagreement is which is separate from the epistemological question of whether they are rationally intractable or irresolvable. This paper aims to remedy this by addressing the metaphysical question of what deep disagreements essentially are.

Chris Ranalli

c.b.ranalli@vu.nl

1 Department of Philosophy, VU University Amsterdam, 11th-12th Floor, De Boelelaan 1105, 1081 HV Amsterdam, The Netherlands
Moreover, addressing the metaphysical question directly has at least two potential payoffs. First, we might think that answers to the metaphysical question can have important ramifications for the epistemological question. For example, if, given the nature of what one disagrees over and one's attitude to it in cases of deep disagreement, it turns out that they aren't genuine disagreements, or they are non-doxastic disagreements, this puts considerable pressure on the idea that they are rationally resolvable. Furthermore, whether epistemic norms apply to deep disagreements will turn, at least in part, on the sorts of psychological attitudes at stake in such cases. So, the thought here is that an inquiry into the metaphysics of deep disagreement promises to shed light on the epistemological question. Secondly, understanding the metaphysics of deep disagreement might help us to draw interesting theoretical connections between deep disagreement and other kinds of disagreement, such as peer disagreement, moral disagreement, religious disagreement, and so on. Indeed, it's not always clear which disagreements are deep. If we have successfully identified general features of deep disagreements, however, this will help us to identify cases of deep disagreement.

The purpose of this paper, then, is to provide a background for our inquiry into the metaphysics of deep disagreement. In particular, I motivate a set of desiderata for

\footnotetext{
${ }^{1}$ See Boghossian (2006), Carter (2016), Kappel (2012), Kusch (2017), and Lynch (2012, 2016).

2 Paradigm cases include Fogelin (2005 [1985]), Lynch (2010), and Pritchard (2011a), among others.
} 
a satisfactory theory of what deep disagreement is, and, as case studies, evaluate two theories in relation to these desiderata. First, what I call the Wittgensteinian theory, inspired by Wittgenstein's (1969) On Certainty, and strongly suggested in the work by Fogelin (2005) and Hazlett (2014), among others, ${ }^{3}$ and secondly the fundamental epistemic principle theory, which finds adherents in recent work by Kappel and Jøch-Klausen (2015), Kappel (2012), and Lynch (2010, 2016).

Here's the structure of the paper. In Sect. 2, I motivate six core desiderata for a theory of what deep disagreement is (henceforth "theory of deep disagreement"). These are desiderata that any theory of deep disagreement needs to satisfy if it is to be an adequate theory of deep disagreement. I argue that the two major theories of deep disagreement in the literature face substantial challenges, challenges which put pressure on the adequacy of these theories. To this end, in Sect. 3, I critically evaluate the Wittgensteinian theory of deep disagreement in relation to these desiderata. I argue that it faces a number of interconnected challenges. The goal here is not to try to refute the Wittgensteinian theory, but rather to pinpoint the major worries one should have with the theory. In Sect. 4, I turn to the fundamental epistemic principle theory of deep disagreement. I argue that it fares better than the Wittgensteinian theory with respect to certain desiderata, at least on certain ways of understanding the Wittgensteinian theory. However, in Sect. 5, I argue that the fundamental epistemic principle theory faces challenges with respect to accounting for the variety of deep disagreement. I argue, then, that both theories are prima facie inadequate.

\section{Desiderata of a Theory of Deep Disagreement}

Let's begin the discussion with an example of a paradigmatic deep disagreement:

Young Earth Creationist: Henry is an Evangelical young Earth creationist, who accepts that the Earth is no more than 6000 years old and a nexus of conspiratorial claims as evidence of why scientists have been misleading us about the age of the Earth. Henry also rejects the theory of evolution and contemporary cosmology, citing literal readings of the Bible: "your denial of scripture is unjustified", he says. Henry's neighbor Richard is a proponent of so-called "New Atheism", and rejects the religious and young Earth creationist views of his neighbor Henry, and asserts that the Earth is much older than 6000 years: "your denial of geology and evolutionary biology are unjustified", he says (cf. Hazlett 2014, pp. 10-11; Lynch 2010, p. 264; Pritchard 2011a, p. 268).

A satisfactory theory of deep disagreement needs to satisfy certain desiderata. These desiderata will act as necessary conditions on the adequacy of the theory. In order to try to identify what these desiderata should be, let's focus on the Young Earth Creationist case as a base case. First, notice that cases like the Young Earth Creationist seem to be genuine disagreements. That is, Henry and Richard disagree over whether the Earth is any older than 6000 years. Intuitively, this is a factual matter: either the Earth is older than 6000 years or it's less than that. Presumably, at least one of them is mistaken.

Secondly, notice that in cases like the Young Earth Creationist, reasons are offered for their views. Richard at least tries to display his reasons for thinking that the Earth is much older than 6000 years to Henry (e.g., he tries to give reasons for believing that it's millions of years old), and Henry at least tries to display his reasons for thinking that the Earth is no more than 6000 years old. Where things go awry is in their receptivity to these (perhaps merely) proffered reasons.

Thirdly, Henry and Richard intuitively not only disagree about the age of the Earth, but many other propositions as well, such as whether God exists, whether creationism is true, whether the fossil record is evidence, and so forth. To put it another way, their disagreement over the age of the Earth might be thought of as proxy for systematic disagreement over various related propositions, propositions related to or constitutive of their world views. So, the thought here is that deep disagreements aren't isolated, but rather extend outwards, having a kind of ripple-effect for what one is committed to disagreeing over in other cases.

Fourthly, their disagreement is persistent. Intuitively, even if they are in principle able to reach agreement on the issues over which they disagree, it's hard to see how they will be able to achieve this result by way of mutually appreciating the reasons they've already cited in favor of their views. For example, if Henry has already cited a religious reason for believing that the Earth was created by God less than 6000 years ago, this is unlikely to move Richard into adopting his view, and vice-versa. This is strikingly different from ordinary cases of disagreement. For example, suppose Johnny and Maria disagree over what the total bill is supposed to be after eating dinner, and Maria is right about

\footnotetext{
3 See Adams (2005), Campolo (2009), Dare (2013), Feldman (2005), Friemann (2005), Phillips (2008), and Turner and Wright (2005).
} 
what the total amount is supposed to be. ${ }^{4}$ If Johnny believes that the total bill is supposed to be $\$ 20$ but Maria believes it's supposed to be $\$ 22$, replaying their reasoning intuitively can move them to change their beliefs. For example, once Johnny identifies a performance error in his initial calculation, or Maria reshows him the bill from the waiter which clearly displays the ' $\$ 22$ ' that Johnny initially failed to notice, ceteris paribus Johnny would change his belief. ${ }^{5}$ And yet this isn't clear at all in cases of deep disagreement. For it looks as if even if the young Earth creationist replays his reasoning for the new atheist, and vice-versa, ceteris paribus it's hard to see why that would move them to change their beliefs. The intuition is that there is something else amiss here which isn't obviously accounted for by way of a performance error or some other contingent defect in their cognition. Importantly, however, persistence needn't entail irresolvability. That the disagreement is irresolvable is one way of explaining its persistence, but it's not obvious that it's the only way. The point is rather that deep disagreements tend to be persistent, even if they are in principle rationally resolvable.

The hypothesis here is that these characteristics are not merely specific to the Young Earth Creationist case. Rather, deep disagreements display theoretical unity, and it's the job of a theory of deep disagreement (of what deep disagreement is) to explain this. For such features can be identified in disagreements between global conspiracy theorists and non-conspiracy theorists, or in cases between religious fundamentalists and non-religious people, among others. Below, I set out what I take to be the plausible desiderata for a satisfactory theory of deep disagreement:

Disagreement: It needs to be consistent with the conflict being a genuine disagreement.

Reason-taking: It needs to be consistent with the view that in cases of deep disagreement, the disagreeing parties at least take themselves to be giving reasons for their views.

Systematicity: It needs to explain why deep disagreements involve systematic disagreement.

Persistence: It needs to explain why deep disagreements tend to be persistent and thus unresolved.

\footnotetext{
4 This kind of case is an adaption of Christensen's famous (2007) restaurant case.

${ }^{5}$ Fogelin (2005 [1985]) placed some weight on the idea that the persistence of the disputants' disagreement not be grounded in their possession or manifestation of intellectual vices. I think what Fogelin had in mind here is not that the disputants in cases of deep disagreement cannot have intellectual vices, but that their intellectual vices aren't the plausible ground of the persistence of deep disagreement, since he thought it was rather the disputants' commitment to different hinge propositions which explains its persistence. See Fogelin (2005, pp. 8-9). Thanks to an anonymous referee for flagging this issue.
}

Some further notes about these desiderata.

One immediate thing to note is that the rational irresolvability of the disagreement is not a plausible constraint on a satisfactory theory of deep disagreement. Let's get clear on what might be meant by this. Notice that 'rational irresolvability' is multiply ambiguous: we might have in mind that (i) there's no epistemically rational way to resolve the disagreement; or that (ii) there's no practically rational way to resolve the disagreement; or further still that (iii) the disagreement isn't resolvable by way of argumentation and the exchange of reasons (e.g., paradigmatic rational methods or ways of resolving disagreements. See Fogelin 2005 [1985] for this view). In the first case, an epistemically rational resolution is simply taking the attitudes they epistemically ought to take towards the contents they disagree over (cf. Feldman 2005). For example, in light of their disagreement, in might be that they ought to be conciliatory, downgrading their degree of confidence; or it might be permissible for them to retain their confidence. The second case can be read as adopting the course of action they practically ought to take, in light of their practical reasons, given their disagreement (see Lynch 2016). And, in the third case, it registers the impossibility of reaching agreement by way of rationally grounded argument. It's also worth noting that if by the 'rational irresolvability' of a deep disagreement it is meant only that there are no purely argument-based reasons which would yield resolution to the disagreement, this doesn't obviously preclude it from being practically rationally resolved or even epistemically rationally resolved. That conclusion would follow only if arguments or the mutual exchange and appreciation of reasons were the only rational way of resolving the disagreement.

Now I think that the rational irresolvability of deep disagreement in any of these senses is not a plausible desideratum for a satisfactory theory of deep disagreement. It's not what we should expect from a satisfactory theory of deep disagreement because it's an open and interesting question whether deep disagreements are rationally resolvable in any of those senses. Presumably, it requires a non-trivial argument to show that they're not resolvable in any of those senses. And there might be such arguments (see Lynch 2010; Fogelin 2005). But it shouldn't be built into what we expect from a theory of what deep disagreement is that they are rationally irresolvable. ${ }^{6}$

\footnotetext{
${ }^{6}$ Indeed, this risks confusing deep disagreement with faultless disagreement. A faultless disagreement is one in which, although the disputants appear to be disagreeing, neither of them are 'at fault' in the sense that neither of them are making any alethic or epistemic mistake. See Kölbel (2004) for this view. Notice that it's a substantive question whether deep disagreements are faultless, just as it's a substantive question whether deep disagreements are rationally resolvable. In both cases, this needs to flow from non-trivial philosophical argument rather than be built into our account of what deep disagreements are in the first place.
} 
Finally, any satisfactory account of deep disagreement needs to address two related questions:

Constitution Question: What do the disputants disagree over in cases of deep disagreement - that is, what are the objects of their disagreement?

Attitude Question: What are the disputants' attitudes to what they disagree over in cases of deep disagreement?

Satisfactory answers to these two questions act as further desiderata. For we should expect that an adequate theory of deep disagreement tells us what people are disagreeing over in such cases (e.g., propositions, rules, norms, etc.) and what their attitudes to the things for which they disagree are supposed to be (e.g., beliefs, non-cognitive attitudes, etc.). The answers to these questions will predictably constrain each other. For example, suppose a theory of deep disagreement said that deep disagreements are primarily disagreements over background non-factual normative rules, rules which tell one what to do or what to believe, but which lack truthevaluable content. ${ }^{7}$ Intuitively, then, this kind of answer to the constitution question would constrain the answer you could give to the attitude question. For example, consider the attitude of belief. Belief takes propositions as its object, and propositions are essentially truth-evaluable contents. So, if one's theory of deep disagreement said that the objects of deep disagreements are non-factual normative rules, then one couldn't say that the disputants' attitudes towards those objects are beliefs. The point is that a satisfactory theory of deep disagreement needs to address these questions because it will tell us about the nature of deep disagreement. For example, it will tell us whether we should expect the disputants' attitudes to conform to epistemic norms, practical norms, both, or neither. It will inform whether we should think that deep disagreement is verbal, faultless, or genuine. Answers to these sorts of questions are what we should expect a theory of deep disagreement to give us.

\section{The Wittgensteinian Theory}

The first theory is inspired by Wittgenstein's final remarks, published as On Certainty (1969), detailing the epistemology of certainty in the context of Moore's (1939) Proof of an External World, the problem of radical skepticism, and the structure of rational evaluation (cf. Pritchard 2011b, 2016a, b). Let's begin with a statement of the view:

\footnotetext{
7 See Hare (1952) for the idea that imperatives are non-factual in the case of moral judgement. See Portner $(2007,2012)$ for the semantics of imperatives. See Boghossian (2008) for a discussion of imperative epistemic rules.
}

Wittgensteinian Theory: Deep disagreements are disagreements over hinge commitments. ${ }^{8}$

This kind of theory is strongly suggested by Fogelin (2005), Hazlett (2014), and Godden and Brenner (2010). ${ }^{9}$ The main component of the theory is the technical term "hinge commitment", of which there are many competing theories. ${ }^{10}$ As a rough and ready characterization, however, hinge commitments are the background presuppositions of our world views and general areas of inquiry, such as physics, history, or geology. In particular, hinge commitments are given a certain epistemic role within our world views and inquiries, such as being:

"unearned certainties" or "standing certainties"-certainties one brings to any normal context. [...] It is the idea of a 'hinge' proposition as a kind of 'certainty of methodology', as it were-a proposition a doubt about which would somehow commit one to doubting not just particular beliefs which we already hold but aspects of the way we habitually praise beliefs. (Wright 2004, p. 38).

The function that Wright highlights here is that doubting a hinge commitment should have the effect of doubting entire areas of inquiry. Compare this with Pritchard (2011b) on of the epistemic role of hinge commitments:

the suggestion is that the very possibility that one belief can count as a reason for or against another belief presupposes that there are some beliefs which play the role of being exempt from needing epistemic support. (Pritchard 2011b, p. 528).

\footnotetext{
${ }^{8}$ Two notes about this view. First, this is not a view I wish to ascribe to Wittgenstein. That is an interpretive issue that is outside the scope of this paper (although there are passages suggestive of this view. See Wittgenstein 1969, §§ 310-316, 608-612). Second, I use the term hinge commitment rather than hinge proposition because it is a controversial matter whether the sentences expressing the hinges are propositions. As such, I use the term 'commitment' to remain neutral on that issue here. See Pritchard (2011b) for an overview.

${ }^{9}$ Here too, I don't want to ascribe to them the Wittgensteinian view of deep disagreement that I discuss in this paper, but rather something in the neighborhood of the Wittgensteinian view. On this score, Fogelin (2005 [1985]) perhaps comes the closest, along with Hazlett (2014). Although, Fogelin's view seems to be a modification of the Wittgensteinian view I discuss here: that deep disagreements are disagreements over some propositions $p, q, r$, where the arguments for those propositions are somehow related to the hinge propositions that the disputants accept. In this fashion, Fogelin seems to endorse what I call a Wittgensteinian view of 'indirect deep disagreement' (see Sect. 3). However, at one point he does suggest that we ought to disagree over the hinge propositions themselves, which would be what I call a 'direct deep disagreement'. See Fogelin (2005, pp. 8-9) and Phillips (2008) for discussion.

${ }^{10}$ For a comprehensive overview, see Pritchard (2016a, b).
} 
What Pritchard stresses is the idea that hinge commitments stand outside our inquiries, as exempt from rational evaluation. Now that we have an initial idea of what hinge commitments are, we might wonder which propositions (or contents) are plausible candidates for being hinges. Here's a recent list from Brueckner:

there is an external world, sense perception is reliable, I am not a brain in a vat, my faculty of reasoning is reliable, the Earth is more than three minutes old, testimony is reliable, memory is reliable. (Brueckner 2007, p. 285).

Notice that while most of the hinge commitments Brueckner lists are epistemic principles, not all of them are. For example, that there is an external world, that I'm not a brain in a vat, and that the Earth is more than three minutes old. One can imagine extending the list to fit with the other plausible candidates (see Coliva 2015). Wittgenstein himself names more:

that no one has ever been far from the Earth (§ 93).

-where everything he has seen or heard speaks for having, in his words, that conviction, and that nothing in his world picture speaks against it (see Wittgenstein 1969 § 93). Likewise:

that there is a brain inside his skull. ( $(118)$.

that the table is still there when no one sees it. ( $\$ 120)$.

that the Earth is round. (§ 146).

\section{Consider also:}

I have a telephone conversation with New York. My friend tells me that his young trees have buds of such and such a kind. I am now convinced that his tree is.... Am I also convinced that the earth exists? (§ 208). The existence of the earth is rather part of the whole picture which forms the starting-point of belief for me. (§ 209).

Wittgenstein's basic idea seems to be that our epistemic practice of giving reasons for belief and doubt presupposes a background of certainties "exempt from doubt" (Wittgenstein $1969 \S \S 341-343$ ). The reason these certainties (however we understand this notion $)^{11}$ are exempt from doubt is that they make our space of reasons possible in the first place.

If the Wittgensteinian theory tells us that all deep disagreements are disagreements over hinge commitments,

\footnotetext{
11 It is outside the scope of this paper to explore this topic here. For competing theories of hinge commitments, see Coliva (2015), MoyalSharrock (2004, 2016), Pritchard (2016a, b), and Wright (2004, 2014). For an overview, see Pritchard (2011b).
}

that raises the question of whether all disagreements over hinge commitments are deep disagreements. ${ }^{12}$ For example, one might think that the disagreement over whether I have hands - a hinge commitment, according to Wittgenstein - is not quite a deep disagreement. At least, it doesn't fit well with the paradigm cases of deep disagreement, such as the Young Earth Creationist case, among others.

However, I think that there is room to account for how some disagreements over whether I have hands, say, is a deep disagreement. First, we need to distinguish between what Thompson Clarke (1972) called plain doubts from unplain doubts, such as those cases when someone doubts the existence of their hands after an experiment or operation (cf. Clarke 1972, p. 758). In these cases, the doubts occur within their world views - these doubts make intuitive sense, given their picture of the world (cf. Stroud 1984, Chaps. $3-5)$. These are the plain doubts. The unplain doubts are the doubts about not just a proposition, or cluster of propositions, but an entire domain or worldview. ${ }^{13}$ In such cases, the proposition I have hands is taken as representative of an entire domain, such as that there are mind-independent physical things, where disagreement about I have hands is representative of the wider domain. ${ }^{14}$

\footnotetext{
12 Thanks to Mark Walker for raising this question.
}

${ }^{13}$ Clarke calls them "philosophical doubts", but his point is that the doubts are intended to proceed without limitation or any epistemic constraints, such as using what one knows to constrain what one doubts. See also Wittgenstein $(1969, \S 20, \S 37)$ for a similar idea.

${ }^{14}$ We need to distinguish between whether such disagreements in philosophical contexts would or tend to leak into non-philosophical contexts with whether such disagreements should do this and whether disputants would be committed to those disagreements having consequences outside of philosophical contexts, given their background commitments in semantics, ontology, and epistemology. For example, suppose the disputants disagree over whether there is an external physical world (EXTERNAL). Disagreement over EXTERNAL, given plausible theses about ordinary objects, commits them to disagreeing over whether they have hands, whether there are trees, buildings, and so forth. In this fashion, if the denier of EXTERNAL continued to believe that, say, there are chairs in their office, they would have a false belief, given their theory. Indeed, they'd have systematically false ordinary object beliefs, given their view, or else they'd need to argue for substantial theses about the content of ordinary object beliefs which preserved the truth of most of their ordinary object beliefs (e.g., that from there are tables, say, it doesn't follow that there are external physical things). The same point applies to higherorder beliefs. For we tend to believe that our ordinary object beliefs are not systematically erroneous, and that other people's self-attributions and third-person attributions on this score are not systematically erroneous either. If the disputants disagreed over EXTERNAL, however, and we held fixed plausible assumptions about the semantic relationships between EXTERNAL and the contents of ordinary object beliefs (such as that if EXTERNAL is false, then so are ordinary objects propositions, such as there are tables), that seems to commit them to not only disagreeing over their first-order ordinary object beliefs, but certain higher-order ordinary object beliefs as well. To be sure, their disagreement wouldn't tend to leak into ordinary contexts, but the point is that they would be committed to having such disagreements, on pain 
We can make sense of such cases within the Wittgensteinian framework. To do this, we need to draw a distinction between direct and indirect deep disagreement. To unpack this distinction, consider a case in which two people disagree over whether some rock is older than 6000 years. This can go in at least two directions. It might be that the disputants are just disagreeing over the age of the rock as such, given certain background geological beliefs and aims. We can imagine one of them arguing that the rock is much older, due to its mineral composition, whereas the other disputant holds that it's much younger, due to its location on the surface. In this kind of case, their disagreement is isolated: nothing much turns on it, just like in the peer disagreement cases, where it's implausible that disagreement over the total restaurant bill, say, has wider implications for their beliefs about arithmetic sums, restaurants, and so on. However, it might also be that their disagreement over the age of that particular rock is a consequence of their deep disagreement over the age of the Earth. To put it more strongly, it might be that the point of their dispute over the age of that particular rock is to hone in on their deeper disagreement over the age of the Earth. In this way, the former is a proxy disagreement for the latter. These disagreements-where the disputants' disagreement over one proposition which doesn't look like a hinge commitment, but which is proxy for a disagreement over a hinge commitment-are indirect deep disagreements.

The basic idea here is that the proponent of the Wittgensteinian theory should draw a distinction between those disagreements which directly concern a hinge commitment, as in the Young Earth Creationist case, and those which indirectly concern a hinge commitment, as in our previous case over the age of some particular rock as proxy for a deep disagreement over young Earth creationism. We can sketch this distinction more generally as follows:

Direct deep disagreement: $S_{1}$ and $S_{2}$ directly deeply disagree about whether $\mathrm{H}$ only if $S_{1}$ and $S_{2}$ disagree over $\mathrm{H}$, and $\mathrm{H}$ is a hinge commitment.

Indirect deep disagreement: $S_{1}$ and $S_{2}$ indirectly deeply disagree about whether $\mathrm{P}$ only if $S_{1}$ and $S_{2}$ disagree over $\mathrm{P}$, and their disagreement over $\mathrm{P}$ commits them to disagreeing over a hinge commitment $\mathrm{H}$.

This distinction also goes towards explaining the systematicity of deep disagreement. For example, if the Earth existed in the distant past such that it's millions of years old or older is a hinge commitment, that commitment intuitively stands in certain logical, probabilistic, and epistemic relations to other propositions. For example, it entails that:

\section{Footnote 14 (continued)}

of inconsistency. The same points can be made for disagreements over external world skepticism.
- The Earth is not merely 6000 years old or less.

And it seems to make it less likely that:

- God created the Earth as early hominids would have found it, ex nihilio.

- There is a global conspiracy that is trying to deceive scientists into thinking that the Earth is much older than it really is, for their own nefarious ends.

Epistemically, it at least seems to speak in favor of propositions like:

- This particular mountain range that I see is much older than the young Earth creationist claims.

- The Himalayas have not been forming only over a short period, less than 6000 years.

- Fossils are not merely planted on the Earth by demons to deceive scientists and the public.

- The Earth has existed for much longer than any human beings have existed.

And it seems to be presupposed by certain domains of inquiry and certain methods, in the following ways:

- Geology is not systematically unreliable.

- Radiocarbon dating is reliable with respect to geological age detection.

Applied to indirect cases of deep disagreement, then, the Wittgensteinian theory will tell us that the young Earth creationist Henry and the new atheist Richard indirectly deeply disagree about whether $\mathrm{P}$ (about whether this particular rock is much older than 6000 years, say, millions of years older) only if they really do disagree over $\mathrm{P}$, and their disagreement over P commits them-whether logically, probabilistically, or epistemically - to disagreeing over a hinge commitment $\mathrm{H}$, say, that the Earth existed in the distant past (e.g., it existed millions of years ago, before any humans existed). In this case, the commitment is logical: Henry and Richard disagree over whether the rock is older than 6000 years old, and this logically commits them to disagreeing over whether the Earth existed in the distant past, so understood. However, it can also be epistemic. To see this, consider:

Young Earth Creationist*: Henry believes that radiocarbon dating is unreliable; that it's just evil forces trying to deceive us. Richard believes that radiocarbon dating is reliable; that it's a highly reliable method for getting true beliefs about the age of Earth's geological formations.

The Wittgensteinian theory will say that Richard's belief here epistemically presupposes the hinge commitment 
that the Earth is very old in the intended sense: presumably, he cannot consistently maintain that we ought to trust radiocarbon dating with regard to geological formations while denying that we shouldn't do so in the numerous cases involving Earth's geological formations. In turn, Henry is epistemically committed to rejecting that the Earth is very old, given his prior belief in the massive unreliability of radiocarbon dating (cf. Coliva 2015, p. 2).

How does the Wittgensteinian theory fare with respect to the desiderata for a satisfactory theory of deep disagreement? We've seen how it can account for the systematicity of deep disagreement. In what follows, I'll explore how well it fares with respect to disagreement, reason-taking, and persistence. I will argue that the degree to which the Wittgensteinian theory can successfully account for the desiderata will turn on their theory of hinge commitments. First, take persistence. In the case where the deep disagreement is indirect, such as in the Young Earth Creationist* case, the explanation of persistence might be that the hinge commitments of their respective contrary beliefs lie in the background. Fogelin entertains this kind of explanation in the following passage:

They [deep disagreements] remain recalcitrant to adjudication because the sources of the disagreement- the framework propositions [the hinge commitments] —are allowed to lie in the background, working at a distance. (Fogelin 2005, p. 8 my additions).

This sort of explanation, however, only helps to explain the persistence of indirect deep disagreement, where the hinge commitments aren't directly scrutinized. The thought is that such disagreements are persistent merely because what's really at issue lies in the background, sheltered from critical attention. However, in the direct cases, this explanation won't work as what's really at issue gets critical attention from the disagreeing parties. Indeed, Fogelin himself goes on to reject this diagnosis of the persistence of deep disagreement. For Fogelin, the source of such persistence is not the fact that the hinge commitments lie in the background, but the fact that-even if brought to the foreground-they are part of a "whole system" of propositions (Fogelin 2005, p. 9 ). The burden on the Wittgensteinian would then be to explain why this fact renders disagreement over hinge commitments persistent, other than the contingent difficulty with assessing 'whole systems' of propositions.

At this juncture, the proponent of the Wittgensteinian theory might argue that pessimism about deep disagreement is true: that such disagreements are rationally irresolvable, that is, there is no epistemically rational response one ought to take, in light of their disagreement, which ought to yield agreement (cf. Feldman 2005 and; Lynch
2010, p. 269). ${ }^{15}$ Recall the argument from Sect. 2 that a theory of deep disagreement should not presuppose that they are rationally irresolvable as part of the theory of what deep disagreement $i s$. If the proponent of the Wittgensteinian theory seeks to explain persistence by reference to pessimism, then they ought to do so by way of an argument from the metaphysics and epistemology of deep disagreement, rather than as part of the analysis of what a deep disagreement is.

One potential challenge for the proponent of the Wittgensteinian theory here is that they might struggle to account for persistence without it thereby turning into an argument for pessimism. To see this, contrast two different accounts of the epistemology of hinge commitments:

(i) The non-epistemic theory, according to which hinge commitments are outside the scope of rational evaluation, and as such are neither justified nor unjustified (see Pritchard 2016a, b; Moyal-Sharrock 2016, 2004), ${ }^{16}$ and:

(ii) The epistemic theory, according to which hinge commitments are within the scope of rational evaluation, and are potentially justified or unjustified, but in a non-paradigmatic way. In particular, our justification for hinge commitments consists in having a default entitlement to trust or accept them, in the absence of evidence or anything which indicates that they're true. (Wright 2004, 2014; Hazlett 2014; Williams 1991)

I will bracket the reasons one might give for supporting these theories, since our focus is on the implications of these theories for deep disagreement. Prima facie, on the non-epistemic theory, there will be a direct argument for the conclusion that pessimism is true. After all, if hinge commitments are neither justifiable nor unjustifiable - that is, they are completely outside the space of epistemic reasonsthen of course the exchange of reasons rationally ought to fail: for those reasons will neither justify the target hinge commitment nor its denial. On the non-epistemic theory, however, it's a much harder question to settle. On the one

\footnotetext{
15 Note that epistemically 'rational resolutions' can come in weaker or stronger forms. A weak rational resolution implies only that the disputants $\mathrm{A}$ and $\mathrm{B}$ take the doxastic attitudes they rationally ought to take to $\mathrm{P}$, even if this continues to yield a disagreement, while a strong rational resolution implies that $\mathrm{A}$ and $\mathrm{B}$ take the doxastic attitudes they rationally ought to take to $\mathrm{P}$ such that this yields agreement. See Matheson (2018).

${ }^{16}$ Note that Moyal-Sharrock and Pritchard are non-epistemicists for different reasons. Moyal-Sharrock $(2004,2016)$ holds that hinge commitments are neither true nor false, and thus not propositions. Pritchard (2016a, b) holds that while hinge commitments are propositions, they are not among the believable propositions.
} 
hand, they won't be able to exchange reasons in the ordinary sense, since they will lack evidence-or in general, anything which favors the truth of their hinge commitment - which rationally ought to get them to retain or change their attitude. On the other hand, the theory permits that there is some degree of rational support for hinge commitments by way of a default non-evidential entitlement to trust them. Provided that one can exchange this non-evidential rational support, then there will be a sense in which disputants can rationally resolve their deep disagreements, namely, by appealing to the hinge commitments that they are mutually entitled to trust. Of course, this would also go towards explaining persistence, as one might think that the explanation of the default entitlement for trusting hinge commitments is not something that will be easily accessible to the disagreeing parties; at least, in many real-world cases of deep disagreement. After all, intuitively the reason why, say, one has a default entitlement to trust that the Earth didn't come into existence five minutes ago won't be something that they can easily work out for themselves. Hence, while the proponent of the non-epistemic theory of hinge commitments will account for persistence by way of rational irresolvability, it is open to the proponent of the epistemic theory to account for persistence by reference to the cognitive opacity of their default entitlement to trust their hinge commitments and the fact that such commitments are non-evidential. In this fashion, the degree to which the proponent of the Wittgensteinian theory will struggle with the persistence desideratum will turn on their theory of hinge commitments generally.

This also relates to the reason-taking desideratum. This says that the theory needs to be consistent with the disagreeing parties taking themselves to be offering rational grounds for their attitude and grounds for their doubts about the other person's attitude. But, of course, whether the theory can do this satisfactorily will depend on the theory of hinge commitments the proponent of the Wittgensteinian theory is working with. For example, if they are working with the non-epistemic theory, they'll need to explain how the disagreeing parties are so easily misled into seeing themselves as giving reasons for their attitudes, when in fact there aren't any to be given. An error theory of their self-perspective will need to be motivated and defended. A similar argument can be made for the epistemic theories. For in these cases, while one can give reasons for or against the hinge commitments, the reasons here are not paradigmatic - that is, they are not evidential or even truth-indicative. However, we typically find that the participants of deep disagreements take themselves to be presenting evidence for their own positive attitude and against their opponent's attitude. (Consider, for example, how exchanges might go between young Earth creationists and new atheists). In this way, even the proponent of the Wittgensteinian account who accepts the epistemic theory of hinge commitments will struggle to not revise our initial thinking about deep disagreements. To be sure, this isn't a knock-down argument against the Wittgensteinian account. Rather, it highlights how even if the Wittgensteinian accepts an epistemic account of hinge commitments, such as that the hinges are true propositions we have a non-evidential entitlement to trust, they'll need to explain why the disputants so easily mistake themselves to be presenting evidence for their view and evidence against their opponent's view.

Finally, satisfying the disagreement desideratum can be problematic for similar reasons, as it will turn on what their theory of hinge commitments is. For example, Wright (2014) takes the relevant attitude connected to hinge commitments to be trust: that one trusts that the hinge commitment is true. ${ }^{17}$ Whether disagreement in propositional trust can constitute genuine disagreement, then, will be a question that needs to be answered. At the very least, it will need to be shown that disagreements in propositional trust retain the mechanics of disagreement in belief, since cases of deep disagreement seem to involve belief. Likewise, consider those theories such as non-propositionalism (MoyalSharrock 2004, 2016; Wright 1985), according to which hinge commitments are non-factual rules-that is, rules which are not truth-apt. Intuitively, since the objects of belief are propositions, it follows that not only can you not believe the hinge commitments, you cannot take any propositional attitude to them whatsoever. And, prima facie at least, that makes it hard to see how disagreement over them is possible. ${ }^{18}$ Of course, this is not to say that the proponent of the Wittgensteinian theory cannot satisfy the disagreement desideratum. Rather, I am arguing that the extent to which they can turns on their theory of hinge commitments. And if one takes seriously the desiderata for an adequate theory of deep disagreement-and one accepts the Wittgensteinian theory of deep disagreement - this should constrain which account of hinge commitments one should accept. ${ }^{19}$

\footnotetext{
17 Wright (2014) argues that the reason our attitudes to hinge commitments shouldn't be beliefs is that entitlement is a non-truth indicating, non-evidential epistemic status, and thus believing that the hinge commitments are true would be irrational. So, Wright opts instead for propositional trust: that we trust that the hinge commitments are true. The idea, I take it, is that belief is essentially regulated by evidential norms, whereas propositional trust isn't.

18 It's of course controversial that disagreement requires belief, but less controversial that disagreement requires doxastic attitudes to a proposition (see Marques 2014), and some way of possibly being accurate/inaccurate (see MacFarlane 2014). What I am claiming here is not quite that non-factualism puts pressure on the disagreement desideratum because you cannot believe the hinge commitments, but rather because you cannot take any propositional attitude to the hinge commitments, much less belief.

19 The two general theories of hinge commitments in the literature are the non-epistemic and the epistemic theories. On Moyal-Sharrock's (Moyal-Sharrock 2016) version of the non-epistemic theory, the hinge commitments are not truth-apt. On Pritchard's (2016) ver-
} 


\section{The Fundamental Epistemic Principle Theory}

In the previous section, I explored the metaphysics of the Wittgensteinian theory of deep disagreement. I argued that, given the desiderata of a satisfactory theory of deep disagreement, it faces a number of challenges.

The first challenge pertains to the persistence desideratum. I argued that how the Wittgensteinian should account for this will turn on their account of hinge commitments more generally. The first theory is the non-epistemic theory, on which hinge commitments are neither justified nor unjustified: they lie outside the space of epistemic reasons altogether. So, we might think that the proponent of the Wittgensteinian theory who accepts a non-epistemic account of hinge commitments will struggle to explain persistence without collapsing into pessimism about deep disagreement, that deep disagreements are rationally irresolvable. And this is problematic because, although pessimism is a viable option, it is prima facie desirable that the persistence of deep disagreement be explained without recourse to it. However, if the Wittgensteinian opts for the epistemic theory instead, on which hinge commitments are justifiable-just not in a paradigmatic way (e.g., not by way of evidence or anything which is truth-indicative) - this provides them with a route to explain persistence without collapsing in pessimism about deep disagreement.

The second challenge pertains to the reason-taking desideratum. For it's hard to see why the disputants would take themselves to be offering grounds for their doubts in the

\footnotetext{
Footnote 19 (continued)

sion, the hinges are truth-apt but not believable, since belief is essentially regulated by epistemic norms whereas our hinge commitments are not. Intuitively, these views will struggle to account for the desiderata. Wright's (2014) epistemic theory, however, says that the hinges are propositions, but you lack evidence for them and you should trust rather than believe them. Yet we might wonder why the Wittgensteinian cannot opt for a theory of hinge commitments on which you can have evidence to believe them. If that's possible, the Wittgensteinian wouldn't struggle with the disagreement, persistence, or reasontaking desiderata. The problem with this view, however, is that it assimilates the epistemology of hinge commitments too closely to the epistemology of our ordinary beliefs, and thus the theoretical utility of hinge commitments is lost. This would be an interesting line to develop, but it's outside the scope of the paper to critically evaluate it here. At least, it's highly contentious in the literature that we could have evidence to believe hinge propositions. One general line of argument is that if we could have evidence which favored believing hinge propositions, then the evidence would need to be more certain for us than the hinge propositions already are, but that nothing is more certain for us than the hinge propositions (cf. Pritchard 2016a, b, p. 65, and; Wittgenstein 1969, § 250, § 115). See Hazlett (2006) for a much weaker idea, namely that our beliefs in hinge propositions, unlike our ordinary beliefs, are not subject to undercutting defeat.
}

other person's commitment if the hinge commitments really were outside the space of reasons. This kind of mistake needs to be explained. After all, we are owed an explanation of why someone would routinely mistake something outside the space of reasons as inside the space of reasons. Moreover, I argued that a similar problem arises for the proponent of the epistemic account of hinge commitments. For while hinge commitments are justifiable on this account—and thus inside the space of epistemic reasons-it is not by way of evidence or anything which indicates that the hinge commitments are true. But cases of deep disagreement seem to be ones in which the disputants present what strikes them as evidence for their beliefs and evidence against their opponent's beliefs. It's not as if the new atheist, for example, thinks that he lacks evidence against the young Earth creationist's beliefs, or lacks evidence for his beliefs, and viceversa. So, even the proponent of the epistemic account of hinge commitments will need to explain why the disputants in such cases make such higher-order mistakes.

The third challenge pertains to the disagreement desideratum. The problem is that there are many theories of hinge commitments, and thus many ways of answering the constitution question (what is the nature of what we disagree over in deep disagreement cases?) and the attitude question (what is the nature of our attitude to what we disagree over in deep disagreement cases?). For example, it's hard to see how we can preserve disagreement over hinge commitments if we take it that hinge commitments are non-factual rules: for then we can neither take propositional attitudes to them, nor will our attitudes be subject to correctness or incorrectness, whether alethic or epistemic, undermining the possibility of disagreement. Of course, this challenge depends on one's account of hinge commitments. On other accounts, such as the epistemic account, the disagreement desideratum is more easily explained.

While I don't consider the problems facing the Wittgensteinian theory to be knock-down objections, I do think it motivates exploring other options. In this section, I want to explore a very similar account of deep disagreement. According to this account of deep disagreement, there is an intimate connection between deep disagreement and epistemic principles. It says that:

Fundamental Epistemic Principle Theory: deep disagreements are disagreements over fundamental epistemic principles.

Let's unpack this theory. Epistemic principles can be normative or evaluative. For example, some epistemic principles say that some belief-forming method is reliable. This ascribes a positive epistemic property (reliability) to a belief forming method (like the method of having a sensory experience as of $\mathrm{P}$ and forming the belief that $\mathrm{P}$ on that basis). Another kind is normative: it says that you ought to do 
something, such as believe, trust, or doubt, given certain epistemic conditions (given your evidence or your epistemic reasons). The discussion here will proceed with both types of epistemic principles in mind, although later it will focus more on normative epistemic principles.

As before, the theory contains a technical term: fundamental epistemic principle. Following Lynch (2010, 2016), we can distinguish between fundamental and non-fundamental epistemic principles. Fundamental epistemic principles are such that they:

[...] can't be shown to be true without employing the source that the relevant principle endorses as reliable. For this reason, explicit defenses of such principles will always be subject to a charge of circularity. (Lynch 2016, p. 250)

Fundamental epistemic principles are about our basic epistemic methods. These might include: "inferential methods like deduction or induction and non-inferential methods, like sense perception" (Lynch 2010, p. 264. cf.; Kappel 2012, p. 10). These methods, in turn, are basic in virtue of the fact that they can't be shown to have the target positive epistemic status without relying on the method in question. So, as many contemporary epistemologists think: ordinary external world belief can be justified by sensory experience, but you cannot show that this belief-forming practice is reliable without employing the method of forming such beliefs on the basis of your sensory experiences. ${ }^{20}$

Although Lynch defines fundamental epistemic principles as principles which ascribe reliability, the basic idea is more general than that. It's that an epistemic principle $\mathrm{F}$ is fundamental in the sense that there is no epistemic reason in favor of $\mathrm{F}$ which does not presuppose $\mathrm{F}$, or presuppose that $\mathrm{F}$ has some positive epistemic status, whether it be reliability or something else (see Kappel 2012, p. 8). As Kappel puts it: "the best epistemic reasons for it are epistemically circular" (Kappel 2012, p. 10).

As it happens, Lynch (2010) himself doesn't seem to endorse the fundamental epistemic principle theory of deep disagreement so stated, but rather a stronger version of it. The stronger version takes it that $\mathrm{S}$ and $\mathrm{S} *$ 's disagreement over $\mathrm{P}$ is deep only if $\mathrm{P}$ is a fundamental epistemic principle, and the following condition holds: "Non-arbitration: There is no further epistemic principle, accepted by both parties [S and $\mathrm{S}^{*}$ ], which would settle the disagreement" (Lynch 2010, p. 265 my addition).

The problem with this stronger version of the view is that it simply builds into the theory of what deep disagreement is that it's irresolvable. But intuitively it shouldn't be a criterion of the disagreement being deep that it's irresolvable tout

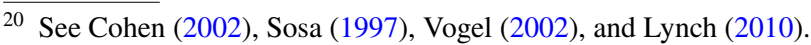

court. Indeed, if such disagreements are rationally irresolvable, for example, this fact should flow from the epistemology of epistemic reasons and the character of deep disagreement, not from the analysis of the phenomenon in question. So, I will work with the weaker formulation of the theory.

How does the fundamental epistemic principle theory fare with respect to the desiderata? Let's first consider systematicity. Recall that, in the Young Earth Creationist case, Henry and Richard's deep disagreement directly concerned the age of the Earth: whether it is younger or older than 6000 years in the intended sense. Henry seemed to endorse that it is younger, while Richard seemed to deny it. This doesn't look like a fundamental epistemic principle but rather a complex quantificational proposition: there is an $x$, $x=$ the Earth, and for every $y$, if $x=y$, then $\neg(y$ is older than 6000 years). To account for how the young Earth creationist case is a deep disagreement, then, the proponent of the fundamental epistemic principle theory will need to say that it is indirectly deep, in that while they don't directly disagree over a fundamental epistemic principle, indirectly they do (replacing hinge commitments with fundamental epistemic principles).

What principle might that be? Lynch (2010) and Kappel (2012) suggest the following kinds of epistemic principles:

Fossil Record: With respect to the facts about the distant past, you ought to conform your beliefs to fit with the evidence from the historical and fossil record. The historical and fossil record is the most reliable method for knowing about the distant past.

Holy Book: With respect to the facts about the distant past, you ought to conform your beliefs to fit with the holy book. The Holy Book is the most reliable method for knowing about the distant past. ${ }^{21}$

Now, the proponent of the fundamental epistemic principle theory needs to explain how these epistemic principles and the content of what Henry and Richard disagree over are related. For starters, they can say that there is an epistemicinferential relation, of the following sort:

Holy Book-Disagreement Link: With respect to the facts about the distant past, you ought to conform your beliefs to fit with the holy book. The holy book says that the Earth is young. So, the Earth is young.

Fossil Record-Disagreement Link: With respect to the facts about the distant past, you ought to conform your beliefs to fit with the evidence from the historical

\footnotetext{
$\overline{21}$ These are what Kappel and Jøch-Klausen (2015) call substantive epistemic norms, norms which "identify specific types of evidence as good, proper, or relevant in any given area of inquiry" (Jønch-Clausen and Kappel 2015, p. 380).
} 
and fossil record. The historical and fossil record say that the Earth is old. So, the Earth is old.

The end of each inferential pattern here is a belief. In the first case, Henry's belief in young Earth creationism, that the Earth is cosmologically very young (thousands of years). In the second case, Richard's belief that the old Earth is cosmologically very old (millions of years).

Next: what are the attitudes of the disagreeing parties to the relevant fundamental epistemic principles? In the case of direct deep disagreement, it seems to be belief. So too, we might claim, it is belief in the indirect case, albeit dispositional belief: what one is disposed to endorse, given their other mental states and habits (it is, after all, implausible that they believe those principles in the active, endorsement sense). That settles the disagreement desideratum.

Now, we should turn to the other desiderata: reason-giving and persistence. It is easy to make sense of both of these desiderata on the fundamental epistemic principle theory, for the only reasons you can (apparently) provide for your fundamental epistemic principles are epistemically circular reasons, and thus they will be as good or as bad as epistemically circular reasons can be. However, it is worth noting that while many epistemologists hold that basic methods and fundamental epistemic principles can, at best, be given epistemically circular justifications, many of them hold that there are additional epistemic considerations which count towards endorsing them.

For example, Crispin Wright (2014) holds that with respect to the epistemic principles of induction, deduction, and perception, we have a default non-evidential entitlement to endorse them. As noted earlier, this default entitlement doesn't count towards the truth of the principles-and thus not towards believing them-but towards trusting them. The thought is that this entitlement is epistemic rather than practical because we will do better epistemically by trusting them rather than distrusting them: we will get more true and useful beliefs rather than false and useless belief. ${ }^{22}$ Relatedly, Burge (2003) argues that we have an a priori entitlement to trust perception, which flows from the nature of perception and its relation to content; Goldberg $(2007,2014)$ makes a similar argument for trusting testimony.

A second kind of consideration is transcendental arguments. These kinds of arguments purport to show that some otherwise unproblematic epistemic condition, such as selfknowledge, self-reference, or knowledge of experience, is a necessary condition of some potentially problematic epistemic condition, such as the reliability of some putative source of justification, such as perception, induction,

22 See Wright (2014) and Hazlett (2006, 2014). For dissent, see Brueckner (2007), Pedersen (2009), and Pritchard (2016a, b). or memory. ${ }^{23}$ For example, McDowell (2006) argues that knowledge of experience is a necessary condition for the trustworthiness of perceptual experience. If the argument succeeds, it would give us an a priori reason to trust perceptual experience. Likewise, Davidson (1984) offers a transcendental argument for the trustworthiness of testimony: roughly, that a necessary condition for the successful interpretation of other speakers is that we are justified in trusting testimony (cf. Coady 1992). Related arguments can be found for the trustworthiness of principles about $a$ priori knowledge and knowledge of content. ${ }^{24}$

Do these two cases problematize the view that persistence is not easily explained by the idea that the best reasons disputants can offer for their fundamental epistemic principles are epistemically circular, such that the disputants' proffered reasons would beg the question against each other? In principle, yes, but in practice, no. In principle, they do because if such reasons are available - that is, entitlement-based or transcendental-based reasons- then they ought to enable the disagreeing parties to reach agreement, since they are in principle appreciable on both sides. In practice, they won't be accessible to the ordinary non-philosopher because they won't know about them. In turn, they won't be available as reasons to exchange. In this way, then, the actual persistence of deep disagreement is easily explained by the fundamental epistemic principle theory.

\section{Challenges for the Fundamental Epistemic Principle Theory}

Although the fundamental epistemic principle theory fares well with respect to the desiderata for an account of deep disagreement, it faces a number of prima facie challenges. These challenges can be summarized as follows:

- Normative non-epistemic deep disagreement: There seem to be deep disagreements which are normative but not epistemic. That is, they are not over epistemic principles in any way. Since the theory tells us that deep disagreements are disagreements over fundamental epistemic principles, we need an account of deep normative disagreement which is not epistemic.

- Non-normative deep disagreement: There seem to be deep disagreements which are not normative at all. That is, the disputants don't seem to be disagreeing over normative contents, but non-normative contents. Since the theory tells us that deep disagreements are disagreements

\footnotetext{
${ }^{23}$ See Stern $(2000)$.

${ }^{24}$ See Peacocke $(1989,2009)$.
} 
over fundamental (normative) epistemic principles, we need an account of non-normative deep disagreement.

In short, the core problem facing the theory is that it's too conservative: for it will only count disagreements over or grounded in fundamental epistemic principles as deep, but this seems to discount clear cases of deep moral and deep metaphysical disagreement, where fundamental epistemic principles aren't obviously involved. In these cases, there's not yet any reason to think they are directly over fundamental epistemic principles or indirectly grounded in them. On this score, the Wittgensteinian theory has an advantage: it can plausibly accommodate the variety of deep disagreement. After all, the property of $<$ being a hinge commitment $>$ is a property that a proposition can have, and there's no in principle reason why metaphysical, epistemological, normative, and moral propositions cannot have that status. Indeed, Wittgenstein himself used 'there are physical objects' as a case in point (Wittgenstein 1969, § 24). Prima facie, then, the Wittgensteinian theory isn't as restrictive as the fundamental epistemic principle theory is on this score.

\subsection{Normative Non-epistemic Deep Disagreement}

For an example of normative non-epistemic deep disagreement, consider deep moral disagreement. This might include disagreements over whether persons have moral status, or whether murder is wrong, among others. Prima facie at least, the fundamental epistemic principle theory has to explain how such deep disagreements are possible, since the content of these disagreements are moral rather than epistemic.

We can develop this problem in a few different ways. The first is that it might seem like there can be deep disagreements over a fundamental moral principle, but which fails to meet the fundamental epistemic principle theory's criteria for being fundamental. If that's right, then there wouldn't be deep disagreements over such principles, which is counterintuitive. The second problem builds on the first: if we suppose that there are fundamental epistemic principles that are part of the disputants' reasons for disagreeing over the fundamental moral principle, then the explanation of what makes the disagreement deep will be that there is a direct (albeit potential) disagreement over the fundamental epistemic principles. But this just assimilates what was supposed to be a deep moral disagreement into a deep epistemic disagreement. The third builds on both of these suggestions: it might be that the disputants believe or disbelieve the fundamental moral principle for no epistemic reasons at all. Perhaps neither of them are motivated by epistemic reasons to believe the truth: what guides their beliefs are their affective attitudes; or perhaps there is only a causal explanation for their opposing beliefs. In this case, what would otherwise seem be to a deep disagreement would need to be counted as shallow.

To see this, consider the moral principle that $(\mathrm{R})$ persons have moral status. This is the kind of principle we might want to count as fundamental (cf. Fogelin 2005). Suppose there can be deep disagreements over (R). This, I submit, is an intuitive view. The problem this raises for the fundamental epistemic principle theory is threefold. First, recall the criterion from Lynch (2010) and Kappel (2012) for thinking that an epistemic principle is fundamental is that the best epistemic support you could get for it would be epistemically circular. Now, it seems like there can be deep disagreements over $(\mathrm{R})$ but that's not yet reason to think that $(\mathrm{R})$ has only epistemically circular reasons in favor of accepting it. For example, it might be that it's morally intuitive; or it might be that God commands it; or that we do better morally by believing than by disbelieving it. If that's right, it follows that a principle like $(\mathrm{R})$ is not fundamental given the relevant criteria, since there might be non-circular epistemic reasons to believe it. So, on the fundamental epistemic principle theory, it looks like there couldn't be deep disagreements about (R), which is counterintuitive.

Now, one might think that two people who disagree over (R) are bound to accept different fundamental epistemic principles, perhaps different fundamental moralepistemic bridge principles, such as principles linking some epistemic condition to the attribution of moral properties (e.g., intuition grounds moral attribution; or God's commands grounds moral attribution). If the disputants accept different fundamental epistemic principles, and this is what explains why the disagreement is deep, then the disagreement over (R) will be an indirect deep disagreement. The direct deep disagreement is over those moralepistemic bridge principles. The problem with this response is that it turns deep moral disagreement into deep epistemic disagreement: there aren't direct deep disagreements over moral principles as such, but over epistemic principles. Further still, it might simply be that each disputant simply endorses or denies (R) without any epistemic reason guiding them at all: perhaps there is only a merely causal explanation of their acceptance or denial of (R). The same argument can be made, mutatis mutandis, for certain axiological and aesthetic disagreements.

Here's a related objection. It's optional that the disputants accept opposing moral-epistemic bridge principles. They might both think that moral intuition is the most basic way for finding out moral truths, and yet disagree over whether moral intuition supports (R): for the people that accept $(\mathrm{R})$, it's plausible that it informs their entire moral worldview, such as which pieces of moral reasoning are good reasoning; which moral judgments are justified; which actions are permissible and forbidden; which plans and policies are worth considering or ignoring, and so on. And it's not clear why a 
disagreement over whether moral intuition supports $(R)$ is what makes the disagreement over $(\mathrm{R})$ deep. The simpler and more elegant explanation is that the disagreement over (R) is itself deep.

A reply to this kind of problem nearly jumps off the page. Why not just reformulate the fundamental epistemic principle theory so that it's not only about epistemic principles, but normative principles more generally? Thus, the theory can be revised along the following lines:

Fundamental Normative Principle Theory: Deep disagreements are disagreements over fundamental normative principles.

This theory has the advantage of being able to account for deep normative disagreement across the board: ethical, epistemic, and practical.

Yet there are two core difficulties with this revised theory as well. The first problem can be overcome, but the second is more formidable; or so I will argue. The first problem is accounting for the fundamentality of the normative principles. The second problem is accounting for non-normative metaphysical disagreement.

\subsection{The Fundamentality Worry}

Let's contrast two kinds of normative principles: imperative principles, principles saying what you are to do (you are to $\phi)$, or simply telling you to do it $(\phi !)$, or that you are to perform the action in certain conditions (in $\mathrm{C}: \phi)$ ). Another kind of normative principle tells you what you ought to do or what you must do, as with 'you ought to $\phi$ ' and 'you must $\phi$ '.

There's a worry with explaining how such principles could be fundamental. In the epistemic case, epistemic circularity was the criterion: epistemic principle $\mathrm{F}$ is epistemically circular when either your best epistemic reason for endorsing $\mathrm{F}$ includes $\mathrm{F}$ or presupposes that $\mathrm{F}$ has the relevant positive epistemic status. By extension, you might think that a normative principle $\mathrm{N}$ is normatively circular when either your best normative reason for endorsing $\mathrm{N}$ includes $\mathrm{N}$ or presupposes that $\mathrm{N}$ has the relevant normative status. For example, it might be that the best normative reason for endorsing that persons have moral status will include or presuppose the fact that persons have some particular moral status (e.g. inalienable rights, or the property of being receptive to right and wrong action). The problem is that this needn't be the case: it might be that such principles tend to be self-evident, but some people enter into an apparently deep disagreement over them because it strikes the first disputant as true and the second as false. Perhaps it should be self-evident to the second person as well, but there is some cognitive block on this feature of the principle for that person; or perhaps the person chooses to reject it for no normative reason, and there is only a causal, psychological explanation for their rejection of it. Of course, there is the option available to the proponent of the fundamental normative principle account to simply deny that such a case $i s$ a deep disagreement. But retaining the view that it is doesn't seem any less plausible either. However, there is another sense of fundamentality one could work with, familiar to logic and mathematics, which is the formal logical-semantic notion. So, we might think that a normative principle $\mathrm{N}$ is fundamental if it is not logically entailed or presupposed by any other normative principle we accept. The problem with this notion of fundamentality here is that it will be trivially satisfied if $\mathrm{N}$ is a conditional imperative, such as 'in $\mathrm{C}$, don't $\phi$ !' (for example: when your evidence doesn't support $p$, don't believe $p$ ), as such conditional norms aren't strictly entailed by anything. Likewise, every categorical imperative, like 'don't $\phi$ !' (for example: don't believe propositions that are not supported by your evidence), would count as well, since it wouldn't even logically follow from itself, as they have no strict implications. Formally, there are no truth-preserving relationships between imperatives of any kind. On such a picture, every imperative principle would thereby be counted as fundamental on the theory, which is too permissive.

However, there might be ways around this problem. The first is to deny that the relevant normative principles are imperatives: so, they won't have the form ' $\phi$ !', or 'If C, $\phi$ !'. A better response is to replace the relevant logical relations with psychological ones, such as that a normative principle $\mathrm{N}$ is fundamental if and only if $\mathrm{N}$ is not derivable from any other norm: if you cannot successfully engage in any type of good reasoning which has the target principle as a conclusion. For example, while 'don't $\phi$ ' does not entail 'in C, don't $\phi$ ', it seems as if an instance of the latter is derivable from the former: without qualification, 'don't $\phi$ ' speaks of any scenario, and commands 'don't $\phi$ ', and thus it speaks of the scenario in which $\mathrm{C}$. So, the fundamentality worry for normative principles lapses here. ${ }^{25}$

\subsection{Metaphysical Disagreement}

Consider metaphysical disagreements over the existence of God, the nature of reality, and so on. Many of these

\footnotetext{
${ }^{25}$ There are two related problems here, but it's outside the scope of the paper to explore them. The first has to do with whether oughtprinciples are truth-apt. See Chrisman (2012). This would pose the same trouble as imperative principles. The second case has to do with moral particularism, the view that there are no general moral principles. This poses the problem that, on such a view, there aren't general fundamental moral principles. Yet, given the criteria, this should weaken our confidence that there are deep disagreements over such principles. Mutatis mutandis for the epistemic analogue of the view, epistemic particularism. See Dancy (2004).
} 
disagreements seem to be deep. Think, for example, of the kinds of inconsistent worldviews at stake: the idealist, immaterialist on the one hand vs. the realist, materialist on the other; or the contrary worldviews at stake, such as the Hindu vs. the evangelical Christian, among others. Prima facie, it's hard to see how the fundamental normative principle theory can account for these kinds of cases, since they needn't be disagreeing over anything normative. Rather, they tend to be over various existential propositions, and other quantificational propositions.

To see this, consider the following case:

BERKELEY'S WORLD: Berkeley accepts that physicalism is false, and that nonphysicalism is true instead: everything is nonphysical. Berkeley accepts idealism, that everything is either a mind or it exists only by virtue of being perceived by a mind. Finally, Berkeley is a theist, and thinks that God exists and sustains the existence of ordinary things by perceiving them. Richard, by contrast, rejects Berkeley's theological, immaterial idealist worldview on every count: he holds that physicalism is true, that realism is true, and that atheism is true.

Berkeley and Richard have a deep metaphysical disagreement. In this case, they don't appear to disagree over anything normative. Of course, the proponent of the fundamental normative principle theory has a reply: surely they disagree so deeply here because they disagree over fundamental normative principles. If so, then BERKELEY's WORLD isn't a problem for the normative principle theory. But here's a twist: suppose they accept the same relevant fundamental epistemic principles, which are:

A priori principle: In metaphysical matters, one ought to conform their beliefs to what their a priori intuition and reasoning tells them.

Common sense principle: In metaphysical matters, one ought to balance their metaphysical judgment with the dictates of common sense.

Both Berkeley and Richard think that they respect these principles. Berkeley thinks that his views flow from good a priori reasoning and intuition, and that they cohere with commonsense (indeed, this was the view of the George Berkeley). Likewise, Richard thinks the same thing. So, they agree on the relevant fundamental epistemic principles. Of course, it might be that they have a higher-order disagreement about the extent to which they do respect those principles, but the point here is that they agree about them. Still, intuitively they have a deep disagreement: BERKELEY's wORLD is certainly a very different world from Richard's; his worldview, with only minds, their ideas, and God anchoring their existence, isn't anything like Richard's. The point, of course, is entirely general. We can build up BERKELEY's
WORLD as follows: Berkeley accepts that there's no external physical world, that persons are nonphysical, that God exists, that moral properties exist, that freedom of the will exists, that there are selves, that Heaven exists, and so on, while Richard denies what Berkeley endorses on every count. This is a disagreement over many existential and universally quantified propositions. Intuitively, this manifests a conflict in worldview, and thus marks a deep disagreement. How can the proponent of the fundamental normative principle theory explain this? On the face of it, they can't. If we only restrict our attention to the list of metaphysical (hinge) propositions that Berkeley affirms and Richard denies, it looks as if it adds up to a deep disagreement. Yet it's hard to see what resources the fundamental normative principle theory has to explain this.

\section{Conclusion}

In the previous section, I argued that the fundamental epistemic principle theory faces two challenges. The first challenge was to explain how normative non-epistemic disagreements are possible. In response, I argued that proponent of the fundamental epistemic principle theory could simply revise their account of deep disagreement to cover normative principles more generally. This gave way to the fundamental normative principle theory in its place. The second challenge was to explain how non-normative deep disagreements are possible. The basic problem was that there seem to be deep metaphysical disagreements which don't depend on conflicts between any normative principles. I concluded that it's hard to see how the proponent of the fundamental normative principle theory could overcome this objection without denying the possibility of deep purely metaphysical disagreement (e.g., disagreements which target only metaphysical hinge propositions). However, I haven't argued that these objections are decisive.

Indeed, this raises the more general question of where we stand on the metaphysics of deep disagreement. For both of the theories I've surveyed seem to make objectionable trade-offs. The Wittgensteinian theory is better able to account for the variety of deep disagreements over the fundamental normative principle theory, whereas the fundamental normative principle theory makes seemingly less revisionary claims about the psychology and the epistemology of the disputants' attitudes in cases of deep disagreement. We might think that this recommends pursuing a theory of deep disagreement which combines aspects of both the Wittgensteinian theory and the fundamental normative principle theory. To this end, the proponent of the fundamental normative principle theory might argue that the Wittgensteinian theory is merely a version of their view. Here's the worry: hinge commitments have 
an epistemic role in the person's worldview, and the fundamental normative principle theory makes the same kind of point about fundamental normative, epistemic principles. So, what's the difference? The difference is twofold. First, the hinge commitments are broader in their form and content: for example, hinge commitments might be categorical, conditional, epistemic, or metaphysical. And you might deny the existence of hinge commitments without thereby denying the existence of normative principles: it seems like the existence of the former is more controversial than the latter. Secondly, while hinge commitments have an epistemic role in the person's worldview, prima facie at least, this role is not the same role attributed to fundamental normative principles. Fundamental normative principles are first principles one might reason from, or act in accordance with. The exact epistemic role of hinge commitments is controversial, but as I made explicit in $\$ 2$, they are not subject to ordinary belief or rational evaluation. But fundamental epistemic principles at least do seem open to ordinary belief and rational evaluation. If anything, then, the point should be taken in reverse: the fundamental normative principle theory looks more like a specification of the Wittgensteinian theory rather a standalone competitor. If that's right, then it will stand or fall with the Wittgensteinian theory.

Of course, one might think that the difference between the two theories really turns on what one's theory of hinge commitments is. At this juncture, one might then say that the main difference between them is a difference in explanatory emphasis. The proponent of the fundamental normative principle theory would say that the disagreement at issue in BERKELEY'S WORLD is derivatively a deep disagreement because they are committed to disagreeing over fundamental epistemic principles, while the Wittgensteinian would say that the disagreement at issue in BERKELEY's WORLD is not derivatively but directly a deep disagreement, because the target propositions function as hinge commitments within their worldviews. In this way, there might only be a subtle difference in what the proponents of each theory take to be explanatorily important.

Acknowledgements I would like to thank Jeroen de Ridder, Thirza Lagewaard, and Mark Walker for their helpful feedback on an earlier version of this paper. I would also like to thank an anonymous referee and the guest editors Pat Bondy and David Godden for their comments and suggestions which greatly improved the paper.

Funding Research for this paper was supported through a Vidi grant (276-20-024) from the Netherlands Organization for Scientific Research (NWO).

\section{Compliance with Ethical Standards}

Conflict of interest Author declares that he has no conflict of interest.
Ethical approval This article does not contain any studies with human participants or animals performed by any of the authors.

Open Access This article is distributed under the terms of the Creative Commons Attribution 4.0 International License (http://creativeco mmons.org/licenses/by/4.0/), which permits unrestricted use, distribution, and reproduction in any medium, provided you give appropriate credit to the original author(s) and the source, provide a link to the Creative Commons license, and indicate if changes were made.

\section{References}

Adams DM (2005) Knowing when disagreements are deep. Informal Logic 25(1):65-77

Boghossian P (2006) Fear of knowledge: against relativism and constructivism. Oxford University Press, Oxford

Boghossian P (2008) Epistemic rules. J Philos 105(9):472-500

Brueckner A (2007) Hinge propositions and epistemic justification. Pac Philos Q 88(3):285-287

Burge T (2003) Perceptual entitlement. Philos Phenomenol Res 67(3):503-548

Campolo C (2009) Deep disagreement in a multicultural world. OSSA Conference Archive 29. http://scholar.uwindsor.ca/ossaarchive/ OSSA8/papersandcommentaries/29

Carter JA (2016) Metaepistemology and relativism. Palgrave Macmillan, Basingstoke

Chrisman M (2012) On the meaning of 'ought'. In: Shafer-Landau R (ed) Oxford studies in metaethics, vol 7. Oxford: Oxford University Press, pp 305-331

Christensen D (2007) Epistemology of disagreement: the good news. Philos Rev 116(2):187-217

Clarke T (1972) The legacy of skepticism. J Philos 69(20):754

Coady CAJ (1992) Testimony: a philosophical study. Oxford University Press

Cohen S (2002) Basic knowledge and the problem of easy knowledge. Philos Phenomenol Res 65(2):309-329

Coliva A (2015) Extended rationality: a hinge epistemology. Palgrave Macmillan, Basingstoke

Dancy J (2004) Ethics without principles. Oxford University Press, Oxford

Dare T (2013) Disagreement over vaccination programmes: deep or merely complex and why does it matter? HEC Forum 26:43-57

Davidson D (1984) Inquiries into truth and interpretation. Oxford University Press, Oxford

Feldman R (2005) Deep disagreement, rational resolutions, and critical thinking. Informal Logic 25:12-23

Fogelin R (2005) The logic of deep disagreements. Informal Logic 25:3-11 (Original, 1985, Informal Logic 7:1-8)

Friemann R (2005) Emotional backing and the feeling of deep disagreement. Informal Logic 25(1):51-63

Godden D, Brenner W (2010) Wittgenstein and the logic of deep disagreement. Cogency 2:41-80

Golberg S (2007) Anti-individualism: mind and language, knowledge and justification. Cambridge University Press, Cambridge

Goldberg S (2007) Anti-individualism: mind and language, knowledge and justification. Cambridge University Press

Goldberg S (2014) Interpersonal epistemic entitlements. Philos Issues 24(1):159-183

Hare RM (1952) The language of morals. Clarendon Press, Oxford

Hazlett A (2006) How to defeat belief in the external world. Pac Philos Q 87(2):198-212 
Hazlett A (2014) Entitlement and mutually recognized reasonable disagreement. Episteme 1:1-25

Kappel K (2012) The problem of deep disagreement. Discip Filos 22(2):7-25

Kappel K, Jønch-Clausen K (2015) Social epistemic liberalism and the problem of deep epistemic disagreements. Ethical Theory Moral Pract 18(2):371-384

Kölbel M (2004) Faultless disagreement. Proc Aristot Soc 104(1):53-73

Kusch M (2017) Epistemic relativism, scepticism, pluralism. Synthese 194(12):4687-4703

Lynch M (2010) Epistemic circularity and epistemic disagreement. In: Haddock A, Millar A, Pritchard D (eds) Social epistemology. Oxford University Press, Oxford

Lynch M (2012) In praise of reason. MIT, Cambridge

Lynch M (2016) After the spade turns: disagreement, first principles and epistemic contractarianism. Int J Study Skept 6:248-259

MacFarlane J (2014) Assessment sensitivity: relative truth and its applications. Oxford University Press, Oxford

Marques T (2014) Doxastic disagreement. Erkenntnis 79(S1):121-142

Matheson J (2018) Deep disagreement and rational resolution. Topoi. https://doi.org/10.1007/s11245-018-9576-y

McDowell J (2006) The disjunctive conception of experience as material for a transcendental argument. Teorema 25:19-33. (Reprinted in the Engaged intellect: philosophical essays. Harvard University Press, 2009, 225-242)

Moore GE (1939) Proof of an external world. Proc British Acad 25(5):273-300

Moyal-Sharrock D (2004) Understanding Wittgenstein's on certainty. Palgrave Macmillan, London

Moyal-Sharrock D (2016) The animal in epistemology. Int J Study Skept 6:97-119

Patterson SW (2015) The methodological usefulness of deep disagreement. Cogency 6(2):39-66

Peacocke C (1989) Transcendental arguments in the theory of content. Oxford University Press, Oxford

Peacocke C (2009) Objectivity. Mind 118(471):739-769

Pedersen NJ (2009) Entitlement, value, and rationality. Synthese 171:443

Phillips D (2008) Investigating the shared background required for argument: a critique of Fogelin's thesis on deep disagreement. Informal Logic 28(2):86-101
Portner P (2007) Imperatives and modals. Nat Lang Semant 15(4):351383. https://doi.org/10.1007/s11050-007-9022-y

Portner P (2012) Permission and choice. In: Grewendorf G, Zimmermann TE (eds) Discourse and grammar. Studies in generative grammar 112. Mouton de Gruyter, Berlin, pp 43-68. http://seman ticsarchive.net/archive/ji1yjmyy/permission_choice_portner.pdf

Pritchard D (2011a) Epistemic relativism, epistemic incommensurability, and Wittgensteinian epistemology. In Hales SD (ed) The Blackwell companion to relativism. Wiley-Blackwell, Malden, pp 266-285

Pritchard D (2011b) Wittgenstein on scepticism. In: Kuusela O, McGinn M (eds) Oxford handbook of Wittgenstein. Oxford University Press, Oxford

Pritchard D (2016) Epistemic angst: radical skepticism and the groundlessness of our believing. Oxford University Press, Oxford

Sosa E (1997) Reflective knowledge in the best circles. J Philos 94:410-430

Stern R (2000) Transcendental arguments: answering the question of justification. Oxford University Press, Oxford

Stroud B (1984) The significance of philosophical scepticism. Oxford University Press

Stroud B (1999) The goal of transcendental arguments. In: Stern R (ed) transcendental arguments: problems and prospects. Oxford University Press, Oxford (Reprinted in Stroud (2000) Understanding human knowledge: Philosophical Essays, Oxford, pp 203-223)

Turner D, Wright L (2005) Revisiting deep disagreement. Informal Logic 25(1):25-35

Vogel J (2002) Reliabilism leveled. J Philos 97 (2000):602-623

Williams M (1991) Unnatural doubts: epistemological realism and the basis of scepticism. Blackwell, Oxford

Williams M (2007) Why (Wittgensteinian) contextualism is not relativism. Episteme 4(1):93-114

Wittgenstein L (1969) In: Anscombe GEM, von Wright GH (eds), Paul D, Anscombe GEM (trans) On certainty. Blackwell, Oxford

Wright C (1985) Facts and certainty. Proc Br Acad 71:429-472

Wright C (2004) Wittgensteinian certainties. In: McManus D (ed) Wittgenstein and scepticism. Routledge, London

Wright C (2014) On epistemic entitlement II: welfare state epistemology. In: Dodd D, Zardini E (eds) Scepticism and perceptual justification. Oxford University Press, Oxford 